\title{
A Cationic [60] Fullerene Derivative Reduces Invasion and Migration of HT-29 CRC Cells in Vitro at Dose Free of Significant Effects on Cell Survival
}

\author{
Marianna Lucafò ${ }^{1, \dagger}, \quad$ Chiara Pelillo ${ }^{1, \dagger}$, Marco Carini ${ }^{2}$, Tatiana Da Ros $^{2}$, Maurizio Prato ${ }^{2}$, Gianni Sava ${ }^{1, *}$
}

(Received 19 November 2013; accepted 07 January 2014; published online 20 March 2014)

\begin{abstract}
Nanomaterials with unique characteristics exhibit favorable therapeutic and diagnostic properties, implying their enormous potential as biomedical candidates. $\mathrm{C}_{60}$ has been used in gene- and drug-delivery, as imaging agents, and as photosensitizers in cancer therapy. In this study, the influences of a cationic functionalized fullerene on cellular behavior of human colorectal cancer cell line (HT-29) were investigated. Results indicated that HT-29 treated with the studied compound showed a lower sensitivity but a significant impairment in migration and invasion by interfering with the activities of matrix metalloproteinases (MMP-2 and 9). The presence of fullerene also altered the capacity of adhesion-related proteins to perform their activity, thereby inducing dramatically adverse effects on the cell physiological functions such as cell adhesion. Thus, our study suggests that this compound is a new potential anti-metastatic effector and a therapeutic component for malignant colorectal cancer.
\end{abstract}

Keywords: Fullerene; Cancer; Anti-metastatic drug; Nanomedicine

Citation: Marianna Lucafò, Chiara Pelillo, Marco Carini, Tatiana Da Ros, Maurizio Prato and Gianni Sava, "A Cationic [60] Fullerene Derivative Reduces Invasion and Migration of HT-29 CRC Cells in Vitro at Dose Free of Significant Effects on Cell Survival", Nano-Micro Lett. 6(2), 163-168 (2014). http://dx.doi.org/10. $5101 / \mathrm{nml} \cdot \mathrm{v} 6 \mathrm{i} 2 \cdot \mathrm{p} 163-168$

\section{Introduction}

Current status of anticancer chemotherapy of solid malignant tumors indicates the necessity for agents active against tumor metastases. Metastasis, the spread of a primary tumor from its initial location to distant localities, is the main cause of death in cancer patients. Colorectal cancer (CRC) can lead to metastasization and represents one of the leading causes of cancer-related mortality [1]. Its progression to a highly advanced, metastatic stage (mCRC) still decreases the overall 5-year survival to less than 8-10\% [2].

The rapid development of nanotechnology and its ap- plications has allowed for a wide variety of nanoparticles to provide a broad range of opportunities in multidisciplinary fields and particularly in medicine, for clinical therapy and diagnosis [3].

Recent reports show that carbon nanomaterials, in particular fullerenes, inhibit various angiogenic signalling pathways and, therefore, can be potentially used in anti-angiogenic therapy [4-7]. Based on these properties, we might expect that fullerenes can have significant effects on tumour metastases either preventing their formation or inhibiting their growth. In this context it might be interesting to note that the endohedral metallofullerenol Gd@ $\mathrm{C}_{82}(\mathrm{OH})_{22}$ has been demon-

\footnotetext{
${ }^{1}$ Department of Life Sciences, University of Trieste, Via Giorgieri 5, 34127, Trieste (TS), Italy

2 Department of Chemical and Pharmaceutical Sciences, University of Trieste, Piazzale Europa 1, 34127, Trieste (TS), Italy

$\dagger$ Contributed equally to this paper.

*Corresponding author. E-mail: gsava@units.it
} 
strated to interfere with the neoplastic growth, as well as with tumour metastasis, in a mouse cancer model, with almost no toxicity to normal cells in vivo and in vitro [8]. Also the water-soluble pristine (unmodified) $\mathrm{C}_{60}$ inhibits the transplantable malignant Lewis lung carcinoma growth and metastasis in $\mathrm{C} 57 \mathrm{Bl} / 6 \mathrm{~J}$ male mice [7]. Limited knowledge exists on the capacity of the fullerenes to interfere with tumor invasion and the mechanism involved in the fullerene anti-metastatic effect remains to be elucidated. To explore this further, the effect of fullerene on key steps of tumor metastasis, including cell adhesion, migration and invasion, was investigated.

Our previous studies demonstrated that a cationic fullerene derivative $\left(\mathrm{C}_{60}+\right)$, a fulleropyrrolidinium salt, was able to effectively inhibit tumor cell proliferation in vitro [9] and, recently published data from our laboratory, obtained by RNA-sequencing on MCF7 cells [10], indicated that the expression profile of several proteins involved in cell-cell adherence junctions was altered when treated by $\mathrm{C}_{60}+$. Therefore, the question if compound $\mathrm{C}_{60}+$ plays a role in the regulation of migration and adhesion of HT-29 colorectal cell line naturally arose.

The present study examined the hypothesis that derivative $\mathrm{C}_{60}+$ participates in colorectal cancer cell invasion. Cells treated with it exhibited significant impairment in a series of preliminary migration and adhesion assays in vitro. Thus, compound $\mathrm{C}_{60}+$ may be a new potential anti-tumor effector and therapeutic component for malignant colorectal cancer.

\section{Experimental}

The synthesis and the characterization of the fullerene derivative $\mathrm{C}_{60}+$ was performed as previously described $[9,11]$.

The human colorectal carcinoma cell line were purchased from the ECACC N ${ }^{\circ} 86012803$ (HT-29). HT29 was maintained in RPMI-1640. The culture medium was supplemented with $10 \%(\mathrm{v} / \mathrm{v})$ fetal bovine serum (FBS), penicillin $(100 \mathrm{U} / \mathrm{mL})$, streptomycin $(100$ $\mu \mathrm{g} / \mathrm{mL}$ ), and L-glutamine $2 \mathrm{mM}$; cells were grown at $37^{\circ} \mathrm{C}$ in a $95 \%$ air and $5 \% \mathrm{CO}_{2}$ humidified incubator.

HT-29 were harvested by trypsinization and plated into 96 -well culture plates at approximately $1.5 \times 10^{4}$ per well. After incubated for $24 \mathrm{~h}$, different concentrations of $\mathrm{C}_{60}+(1,5,10,25$ and $40 \mu \mathrm{M})$ dissolved in culture medium were added to each well. Then the samples were incubated $48 \mathrm{~h}$ at $37^{\circ} \mathrm{C}$ in the humidified atmosphere $\left(5 \% \mathrm{CO}_{2}\right)$. The colorimetric $3-(4,5$ dimethylthiazol-2-yl)-2,5-diphenyl tetrazolium bromide (MTT) assay was performed to assess the metabolic activity of cells treated as described above. $20 \mu \mathrm{l}$ stock MTT $(5 \mathrm{mg} / \mathrm{mL})$ were added to each well, and cells were then incubated for $4 \mathrm{~h}$ at $37^{\circ} \mathrm{C}$. Cells were lysed with isopropanol $\mathrm{HCl} 0.04 \mathrm{~N}$. Absorbance was measured at 540 and $630 \mathrm{~nm}$ using a microplate reader (Automated Microplate Reader EL311, BIOTEK@ Instruments, Vermont, USA). All measurements were done in six replicates, and at least three independent experiments were carried out.

A 96-well plate was pre-coated with fibronectin, collagen I, collagen IV, Poly-L-lysine, laminin (SigmaAldrich, St. Louis, USA) and Matrige ${ }^{\mathrm{TM}}(20 \mu \mathrm{g} / \mathrm{ml})$ for $4 \mathrm{~h}$ at $37^{\circ} \mathrm{C}$ or $4^{\circ} \mathrm{C}$ overnight and subsequently blocked with PBS-BSA $0.1 \%(\mathrm{w} / \mathrm{v})$ for $15 \mathrm{~min}$ at $37^{\circ} \mathrm{C}$. Sub confluent tumor cells were treated with $\mathrm{C}_{60}+(25 \mu \mathrm{M})$ for $48 \mathrm{~h}$ and then grown in serum-free medium for additional $24 \mathrm{~h}$. Cells were trypsinized with $1 \mathrm{mM}$ EDTA, resuspended in serum free medium with $0.1 \%$ BSA for $30 \mathrm{~min}$ at room temperature to ensure re-expression of integrins on the cell surface and seeded in the plate $\left(5 \times 10^{4}\right.$ cells/well). HT-29 were allowed to attach to each substrate for $1 \mathrm{~h}$ at $37^{\circ} \mathrm{C}$ and subsequently fixed with trichloroacetic acid $10 \%(\mathrm{v} / \mathrm{v})$ for $1 \mathrm{~h}$ at $4^{\circ} \mathrm{C}$ and stained with sulphorodamine B $0.4 \%(\mathrm{w} / \mathrm{v})$. The absorbance was read at $570 \mathrm{~nm}$ and related to the adhesion rate.

Effects of the $\mathrm{C}_{60}+$ to inhibit cancer cells motility were tested performing a conventional Boyden chamber assay.

HT-29 cells, sown $72 \mathrm{~h}$ before, were left in serum-free medium containing $0.1 \%$ bovine serum albumin (BSA) for $24 \mathrm{~h}$ after being treated with $\mathrm{C}_{60}+(25 \mu \mathrm{M})$ for $48 \mathrm{~h}$, at $37^{\circ} \mathrm{C}$. At the end of the treatment, $5 \times 10^{4}$ cells were sown in $200 \mu \mathrm{L}$ of serum-free medium containing $0.1 \%$ $\mathrm{BSA}$, in the upper side of a polyvinylpirrolidone-free polycarbonate filter $(6.5-\mathrm{mm}$ diameter and $8-\mu \mathrm{m}$ pore size) set in a Transwell $(\mathrm{R}$ ) cell culture chamber (Corning Costar Italia, Milan, Italy) in triplicate. The lower compartment was filled with the appropriate culture medium, supplemented with $10 \%$ FBS. Plates were left in the incubator for $72 \mathrm{~h}$, at $37^{\circ} \mathrm{C}, 5 \% \mathrm{CO}_{2}, 100 \%$ relative humidity. At the end of the incubation, cells that had not invaded were mechanically removed from the upper surface of the filter by wiping them with a cotton bud. Cells that had migrated to the lower surface were fixed with $1.1 \%$ glutaraldehyde for $15 \mathrm{~min}$, washed

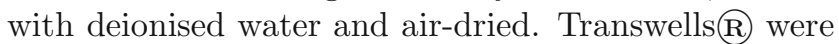
then stained with $0.1 \%$ crystal violet in $200 \mathrm{mM}$ borate buffer, $\mathrm{pH} 9.0$ for $20 \mathrm{~min}$ at room temperature. After washings with deionised water and complete drying, the dye was dissolved in $10 \%$ acetic acid and the absorbance was read at $590 \mathrm{~nm}$ by a SpectraCount spectrophotometer (Packard Bell, Meriden, CT, USA).

Invasive capability was measured in a Transwell $\mathbb{R}$ cell culture chamber (Corning Costar Italia, Milan, Italy) according to a method modified from Albini et al. [12]. In brief, the surface of a polyvinylpirrolidone-free polycarbonate filter $(6.5-\mathrm{mm}$ diameter and $8-\mu \mathrm{m}$ pore 
size) was coated with $30 \mu \mathrm{g}$ per $50 \mu \mathrm{L}$ of Matrigel $\mathrm{R}$. (Beckton Dickinson, Bedford, MA, USA) diluted in DMEM and air-dried overnight at room temperature. The filters were reconstituted with DMEM immediately before use. HT-29 cells, sown $72 \mathrm{~h}$ before, were left in serum-free medium containing $0.1 \%$ bovine serum albumin (BSA) for $24 \mathrm{~h}$ after to being treated with $\mathrm{C}_{60}+$ $(25 \mu \mathrm{M})$ for $48 \mathrm{~h}$, at $37^{\circ} \mathrm{C}$. At the end of the treatment, cells were harvested with trypsin-EDTA, and $5 \times 10^{4}$ cells were sown in $200 \mu \mathrm{L}$ of serum-free medium containing $0.1 \% \mathrm{BSA}$, in the upper compartment chamber, in triplicate. The lower compartment was filled with the appropriate culture medium, supplemented with $10 \%$ FBS. Plates were left in the incubator for $96 \mathrm{~h}$, at $37^{\circ} \mathrm{C}$, $5 \% \mathrm{CO}_{2}, 100 \%$ relative humidity. At the end of the incubation, the plate was processed as described in the migration assay.

To perform gelatin zymography, supernatant was collected from sub confluent cell culture treated for $48 \mathrm{~h}$ with $\mathrm{C}_{60}+$ and left $24 \mathrm{~h}$ in serum-free medium. Proteins present in the supernatant were concentrated by centrifugation and quantified using Nano Drop spectrophotometer. $180 \mu \mathrm{g}$ of total mixture of proteins were separated on $10 \%$ polyacrylamide gel containing $0.06 \%$ gelatin (Sigma-Aldrich, St. Louis, USA). Then the gel was washed for 30 minutes using $2.5 \%$ Triton X100 solution to remove SDS and then incubated in an activating buffer $\left(50 \mathrm{~mm} \mathrm{pH} 7.5\right.$ TRIS, $5 \mathrm{mM} \mathrm{CaCl}_{2}$, $0.2 \mathrm{M} \mathrm{NaCl}$ ) for $20 \mathrm{~h}$ at $37^{\circ} \mathrm{C}$. Gelatinase activity was demonstrated by gel staining with $0.5 \%$ Commasie blue and destaining with $30 \%$ methanol solution and $10 \%$ acetic acid. To assess activity, the stained gel was photographed and analyzed using ImageJ software.

Data were subjected to computer-assisted analysis by Graph Pad Instat 3 and statistical significance or regression analysis, were reported in the text.

\section{Results and discussion}

\section{Fullerene derivative $\mathrm{C}_{60}+$ inhibited HT-29 pro- liferation}

The effects of $\mathrm{C}_{60}+$ (Fig. 1(a)) on the viability of HT29 cells after $48 \mathrm{~h}$ challenge with concentrations ranging from 1 to $40 \mu \mathrm{M}$ are reported in Fig. 1(b). $\mathrm{C}_{60}+$ caused a statistically significant reduction of cell viability (about $40 \%$ inhibition), as determined by the MTT test only at the highest dose tested, being the other dosages only marginally capable to influence HT-29 cell growth during the experiment. This result is consistent with unpublished data showing different degrees of cytotoxicity of this fullerene derivative in vitro on a number of tumor cell lines: MCF7 cells were particularly sensitive to the cytotoxic effects [9], whereas other cell lines, e.g. MDA-MB231, were much less sensitive, as reported here for HT-29 cells. The scenario depicted by our RNA-seq analysis suggested that $\mathrm{C}_{60}+$ induced an alteration of the gene expression targeting mTOR signaling at different levels in MCF7 cell line [10]. Among the many factors potentially determining an inhibition of mTOR signaling, we proposed a decrease of available cellular energy as the most plausible. We here hypothesize that the mechanism of action of $\mathrm{C}_{60}+$ in the HT-29 cell line could be the same, given that HT-29 represents a cell line with high in vitro invasive and in vivo metastatic behavior.
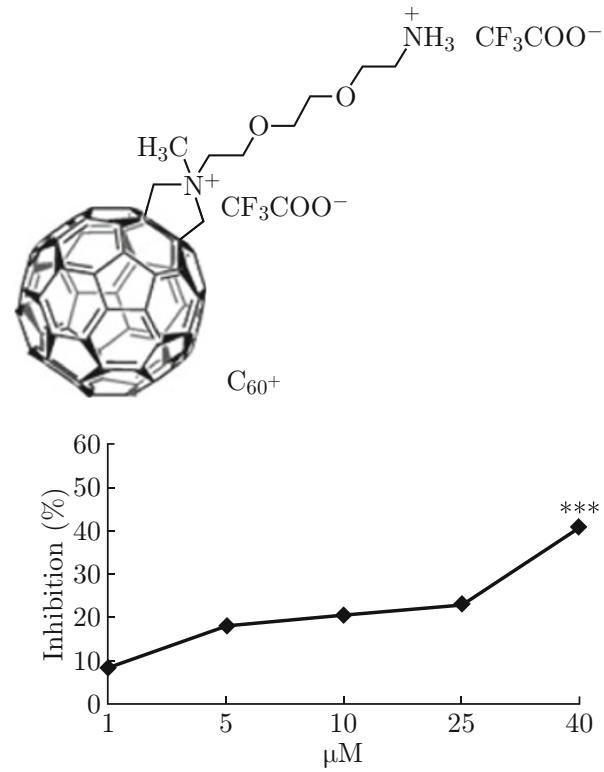

Fig. 1 (a) Chemical structure of fullerene derivative $\mathrm{C}_{60}+$; (b) Effect of $\mathrm{C}_{60}+$ on proliferation of Colon Cancer Cell Line (HT-29). The cells were treated for $48 \mathrm{~h}$ at different concentrations. Each value represent the mean of 3 separate experiments, each with at least three independent samples, \pm S.D. $(* * *) p<0.01$

\section{Cell adhesion analysis}

Cell adhesion to the extracellular matrix (ECM) is an important step that regulates different cellular functions including cell migration and proliferation, differentiation, and tissue organization [13]. This event is mediated by cell surface receptors, the integrins, $\alpha$ and $\beta$ chain heterodimers with short cytoplasmic tails, the enzymatic activity of which activates a variety of intracellular signalling pathways [14]. Integrins were shown to be involved in the processes of cancer cell invasion and metastasis [15], and, most notably, the integrinECM interactions were also demonstrated to have a role for cell survival and resistance to chemotherapy in many types of solid cancers, including colon cancer [16].

In order to mimic the detachment of metastatic cells from the primary mass and their adhesion in a secondary site, we performed a study where HT-29 cells 
were exposed to $\mathrm{C}_{60}+$ at $25 \mu \mathrm{M}$ for $48 \mathrm{~h}$, then harvested from the plate and allowed to adhere to different substrates components of the ECM such as laminin, fibronectin and collagens. Data reported in Table 1 show that $\mathrm{C}_{60}+$ causes a similar inhibition of the adherence ability of HT-29 cells independently whether the substrate used was a component of the ECM, an unspecific substrate (poly-L-lysine) or no substrate at all. However, in all the cases, the HT-29 cells, after such treatment, showed a marked reduction (60-70\% inhibition) of their ability to adhere as compared to untreated cells.

Table 1 Inhibitory potential of $\mathrm{C}_{60}+$ to the interaction between HT-29-ECM substrates. After treatment with $\mathrm{C}_{60}+$, cells were seeded on 96-well plate functionalized with fibronectin, collagen I and IV, laminin, poly-L-lysine and Matrigel $(20 \mu \mathrm{g} / \mathrm{mL})$ and left to adhere $1 \mathrm{~h}$ at $37^{\circ} \mathrm{C}$ with $5 \% \mathrm{CO}_{2}$. Unbound cells were removed while adhered cells were fixed, stained with sulphorodamine $B$ and absorbance read at $570 \mathrm{~nm}$. Results obtained for each substrate are expressed as percentage of adhesion inhibition of treated HT-29, considering the untreated HT-29 adhesion value as $100 \%$

\begin{tabular}{cc}
\hline Substrate & \% Inhibition of Adhesion by $\mathrm{C}_{60}+$ \\
\hline No substrate & 78 \\
Poli-L-lys & 69 \\
Laminin & 63 \\
Fibronectin & 66 \\
Collagen I & 68 \\
Collagen IV & 62 \\
\hline
\end{tabular}

This effect might be related to a number of hypotheses. Integrins might be activated by extracellular events, aside from the intracellular signaling events [17], such as ligand binding, divalent cation concentration, mechanical stress, all of them potentially perturbated by the fullerene treatment. However it must be taken into account also the possible effect of this compound on cell viability that, although not leading to cell death, might keep the treated cells to a lower stage of "biological activity".

\section{Cell migration, invasion and zymography assays}

Migration and invasion are two essential steps of the pathological events leading to cancer metastasis. We studied cell migration using a conventional Boyden chamber assay (Fig. 2(a)).

HT-29 cells, treated with $\mathrm{C}_{60}+$ for $48 \mathrm{~h}$, were left to migrate for $72 \mathrm{~h}$ from the upper chamber through the insert, following the chemotactic signal (serum) coming from the lower side of the chamber. Data reported in Fig. 2(a) shows a pronounced $(80 \%)$ and statistically significant reduction of the migration ability of the treated cells as compared to control constituted by untreated HT-29 cells.
Similar effects were obtained when we studied the invasion process. In this case, cells were seeded on a layer of matrigel previously deposed on the Boyden chamber grid and evaluated after $96 \mathrm{~h}$. Compound $\mathrm{C}_{60}+$ inhibited more than $75 \%$ the capacity of the treated HT-29 cells to cross the matrigel barrier and to accumulate in the lower compartment of the chamber (Fig. 2(b)).

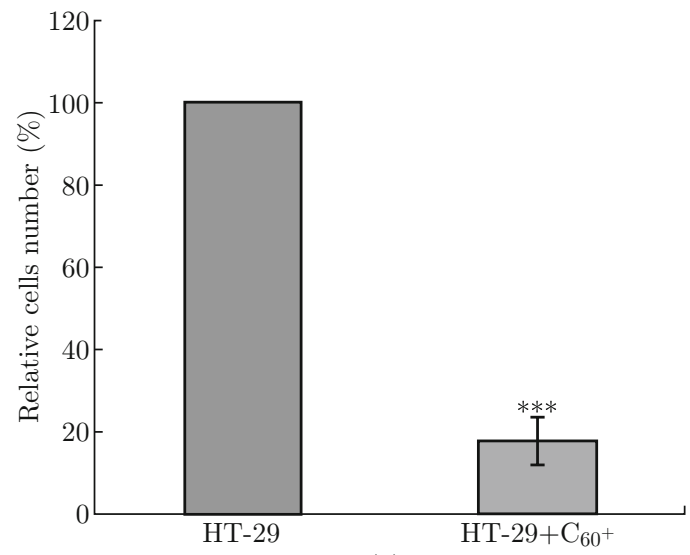

(a)

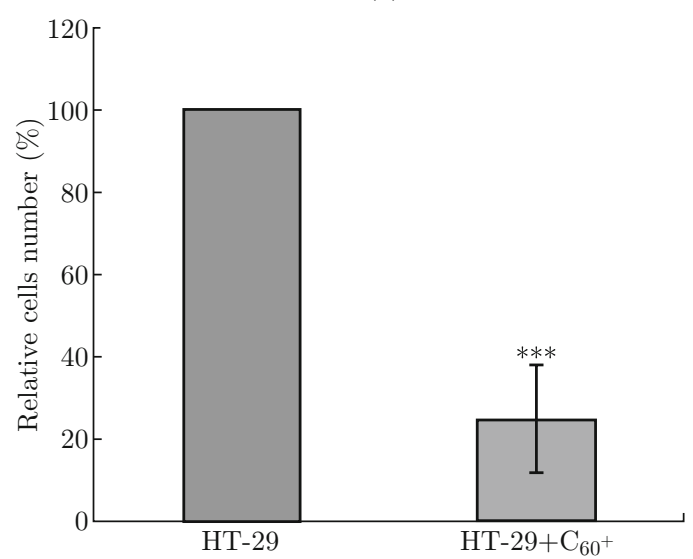

(b)

Fig. 2 (a) Boyden chamber assay: HT-29 cells were treated with $\mathrm{C}_{60}+$ for $48 \mathrm{~h}$ and then seeded in a Boyden chamber and left to migrate for $72 \mathrm{~h}$. At the end of this time, cells that migrated were fixed, stained with crystal violet and the absorbance read at $590 \mathrm{~nm}$. Statistical analysis was performed with ANOVA Unpaired t test-One tail t test $(* * *)$ $p<0.0001$ vs control (HT-29). (b) Invasion assay: HT29 treated $48 \mathrm{~h}$ with $\mathrm{C}_{60}+$ were seeded on the upper side of inserts functionalized with matrigel and were left invade $96 \mathrm{~h}$. At the end of incubation, cells on the lower side of the inserts were fixed, stained with crystal violet and the absorbance read. Statistical analysis was performed with ANOVA Unpaired t test-One tail t test $(* * *) p<0.0001$ vs HT-29.

The compared analysis of the effects of $\mathrm{C}_{60}+$ on migration and invasion suggests that this compound does not reduce the capacity of HT-29 cells to degrade the ECM. In fact, it seems that the effects of the considered fullerene derivative on these cells might consist of a more general reduction of the cells ability to move or a 
reduced capacity to respond to the chemotactic signal, operated by the serum present in the lower wall. On the contrary, the treated cells have a reduced gelatinolytic ability, as shown by a study of MMP2 and MMP9 activity, performed on the supernatant obtained by the HT-29 cells exposed to $\mathrm{C}_{60}+$ at $25 \mu \mathrm{M}$ for $48 \mathrm{~h} \mathrm{(38-}$ $42 \%$ inhibition, Fig. 3), suggesting that the treated cells have a lower capacity to degrade the ECM.

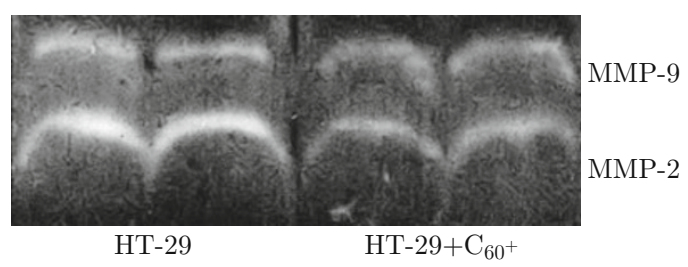

Fig. 3 Gelatinolytic activity of MMP-2 and MMP-9 was evaluated in HT-29 cells treated with $\mathrm{C}_{60}+$ at $48 \mathrm{~h}$.

The activation of the zymogen form of MMP2 (proMMP2) is a cell-surface event that is mediated by members of the membrane-type (MT) subfamily of MMPs as MT1-MMP and by the tissue inhibitor of metalloproteinase (TIMP-2), a member of the family of MMP inhibitors $[18,19]$. It has been demonstrated that this inhibitor directly interacts with MMP2 or through MT1MMP/TIMP-2 complex formation reducing the enzymatic activity of MMP2 [20-22].

Recently we found that $\mathrm{C}_{60}+$ increases 4 -folds the expression level of TIMP-2 after 24 and $48 \mathrm{~h}$ of treatment [10] in the human breast cancer cell line MCF7. This result could suggest a similar effect of this compound also on HT-29 colon cancer cell line and a consequent reduced gelatinolytic activity of MMP2 detected after treatment of cells with fullerene $\mathrm{C}_{60}+$.

Moreover the complex pro-MMP2 and TIMP-2 is able to inhibit other MMPs such as MMP9 through the formation of a ternary complex pro-MMP2-TIMP2-MMP9 [23-25]. This data suggest that the reduced MMP9 activity detected in treated HT-29 cells, could be due to the increased level of TIMP-2 after $\mathrm{C}_{60}+$ treatment and its modulation on MMP9 activity via MMP2 involvement.

\section{Conclusions}

The in vitro study of fullerene derivative $\mathrm{C}_{60}+$ on the ability of HT-29 cells to migrate and invade, events that mimic important steps of the process of metastasis formation, showed promising effects. The compound, in fact, inhibited the capacity of HT-29 cells to re-adhere, to migrate and to invade and these effects were, at least in part, associated with the decrease of the gelatinolytic activity of the treated cells. The treated HT-29 cells did not present significant differences in the adherence process in presence of the various ECM substrates and this seems to rule out an effect of $\mathrm{C}_{60}+$ on cell integrins. Rather, it seems that $\mathrm{C}_{60}+$ might act on a more generalized pathway responsible for multiple effects of the metastatic capacity of the cells.

Anyhow, these data, although preliminarily and considering the role attributed to phenomena such as adhesion and migration for the process of metastasis formation suggest the ability of this fullerene derivative to interfere with metastases of solid tumors, in agreement with other data already reported in the literatures $[7,8]$.

\section{Acknowledgements}

The work was funded within the research contracts Nanocancer Friuli Venezia Giulia, Fra-2011 University of Trieste, and by Italian Ministry of Education MIUR (FIRB RBAP11ETKA and PRIN 2010N3T9M4_001). Thanks to Callerio Foundation Onlus for supporting the fellowship grant to Marianna Lucafò and Chiara Pelillo.

\section{References}

[1] A. Jemal, R. Siegel, J. Xu and E. Ward, "Cancer statistics, 2010", CA Cancer J. Clin. 60(5), 277-300 (2010). http://dx.doi.org/10.3322/caac. 20073

[2] J. M. Davies and R. M. Goldberg, "Treatment of metastatic colorectal cancer", Semin. Oncol. 38(4), 552-60(2011). http://dx.doi.org/10.1053/j. seminoncol.2011.05.009

[3] K. K. Jain, "Nanotechnology in clinical laboratory diagnostics", Clin. Chim. Acta 358 (1-2), 37-54 (2005). http://dx.doi.org/10.1016/j.cccn.2005.03.014

[4] P. Chaudhuri, R. Harfouche, S. Soni, D. M. Hentschel, and S. Sengupta, "Shape effect of carbon nanovectors on angiogenesis", ACS Nano 4(1), 574-82 (2010). http://dx.doi.org/10.1021/nn901465h

[5] M. Grodzik, E. Sawosz, M. Wierzbicki, P. Orlowski, A. Hotowy, T. Niemiec, M. Szmidt, K. Mitura and A. Chwalibog, "Nanoparticles of carbon allotropes inhibit glioblastoma multiforme angiogenesis in ovo", Int. J. Nanomed. 6, 3041-3048 (2011). http://dx.doi.org/ 10.2147/I JN.S25528

[6] M. Wierzbicki, E. Sawosz, M. Grodzik, M. Prasek, S. Jaworski and A. Chwalibog "Comparison of antiangiogenic properties of pristine carbon nanoparticles", Nanoscale Res. Lett. 8(1), 195 (2013). http:// dx.doi .org/10.1186/1556-276X-8-195

[7] S. V. Prylutska, A. P. Burlaka, Y. I. Prylutskyy, U. Ritter and P. Scharff, "Pristine C(60) fullerenes inhibit the rate of tumor growth and metastasis", Exp Oncol 33(3), 162-164 (2011).

[8] C. Chen, G. Xing, J. Wang, Y. Zhao, B. Li, J. Tang, G. Jia, T. Wang, J. Sun, L. Xing, H. Yuan, Y. Gao, H. Meng, Z. Chen, F. Zhao, Z. Chai and X. Fang, "Multihydroxylated $\left[\mathrm{Gd} @ \mathrm{C}_{82}(\mathrm{OH})_{22}\right]_{n}$ nanoparticles: Antineoplastic activity of high efficiency and low toxi- 
city", Nano Lett. 5(10), 2050-2057 (2005). http://dx. doi.org/10.1021/nl051624b

[9] M. Lucafò, S. Pacor, C. Fabbro, T. Da Ros, S. Zorzet, M. Prato and G. Sava, "Study of a potential drug delivery system based on carbon nanoparticles: Effects of fullerene derivatives in MCF7 mammary carcinoma cells", J. Nanopart. Res. 14, 1-13 (2012). http://dx. doi.org/10.1007/s11051-012-0830-8

[10] M. Lucafò, M. Gerdol, A. Pallavicini, S. Pacor, S. Zorzet, T. Da Ros, M. Prato and G. Sava, "Profiling the molecular mechanism of fullerene cytotoxicity on tumorcells by RNA-seq", Toxicology 314(1), 183-192 (2013). http://dx.doi.org/10.1016/j.tox. 2013.10.001

[11] K. Kordatos, T. Da Ros, S. Bosi, E. Vazquez, M. Bergamin, C. Cusan, F. Pellarini, V. Tomberli, B. Baiti, D. Pantarotto, V. Georgakilas, G. Spalluto and M. Prato, "Novel versatile fullerene synthons", J. Org. Chem. 66, 4915-4920 (2001). http://dx.doi.org/10. 1021/jo015608k

[12] A. Albini, Y. Iwamoto, H. K. Kleinman, G. R. Martin, S. A. Aaronson, J. M. Kozlowski and R. N. McEwan, "A rapid in vitro assay for quantitating the invasive potential of tumor cells", Cancer Res. 47(12), 3239-45 (1987).

[13] P. Provenzano and P. J. Keely, "Mechanical signaling through the cytoskeleton regulates cell proliferation by coordinated focal adhesion and Rho GTPase signalling", J. Cell Sci. 124 (Pt8), 1195-1205 (2001). http://dx.doi.org/10.1242/jcs.067009

[14] F. G. Giancotti and E. Ruoslahti, "Integrin signaling", Science 285(5430), 1028-1032 (1999). http://dx.doi. org/10.1126/science. 285.5430.1028

[15] J. D. Hood and D. A. Cheresh, "Role of integrins in cell invasion and migration", Nature Rev. Cancer 2(2), 91-100 (2002). http://dx.doi.org/10.1038/nrc727

[16] F. Aoudjit and K. Vuori, "Integrin signaling in cancer cell survival and chemoresistance", Chemother. Res. Pract. 1-16 (2012). http://dx.doi.org/10. $1155 / 2012 / 283181$

[17] M. Millard, S. Odde and N. Neamati, "Integrin targeted therapeutics", Theranostics 1, 154-188 (2011). http://dx.doi.org/10.7150/thno/v01p0154
[18] S. Hernandez-Barrantes, M. Bernardo, M. Toth, and R. Fridman, "Regulation of membrane type-matrix metalloproteinases", Semin. Cancer Biol. 12(2), 131138 (2002). http://dx.doi.org/10.1006/scbi. 2001. 0421

[19] H. Sato, T. Takino, Y. Okada, J. Cao, A. Shinagawa, E. Yamamoto, and M. Seiki, "A matrix metalloproteinase expressed on the surface of invasive tumour cells", Nature 370(6484), 61-65 (1994). http://dx. doi.org/10.1038/370061a0

[20] A. Y. Strongin, B. L. Marmer, G. A. Grant and G. I. Goldberg "Plasma membrane-dependent activation of the $72-\mathrm{kDa}$ type IV collagenase is prevented by complex formation with TIMP-2", J. Biol. Chem. 268(19), 14033-14039 (1993).

[21] Q. Nguyen, F. Willenbrock, M. I. Cockett, M. O'Shea, A. J. Docherty and G. Murphy, "Different domain interactions are involved in the binding of tissue inhibitors of metalloproteinases to stromelysin- 1 and gelatinase A", Biochem. 33(8), 2089-2095 (1994). http://dx.doi.org/10.1021/bi00174a015

[22] M. Bernardo and R. Fridman, "TIMP-2 (tissue inhibitor of metalloproteinase-2) regulates MMP-2 (matrix metalloproteinase-2) activity in the extracellular environment after pro-MMP-2 activation by MT1 (membrane type 1)-MMP", Biochem. J. 374 (Pt3), 739-745 (2003). http://dx.doi.org/10.1042/ BJ20030557

[23] P. Vempati, E. D. Karagiannis and A. S. Popel "A Biochemical Model of Matrix Metalloproteinase 9 Activation and Inhibition", J. Biol. Chem. 282(52), 37585-37596 (2007). http://dx.doi.org/10.1074/ jbc. M611500200

[24] H. Kolkenbrock D. Orgel, A. Hecker-Kia, W Noack, N. Ulbrich "The complex between a tissue inhibitor of metalloproteinases (TIMP-2) and $72-\mathrm{kDa}$ progelatinase is a metalloproteinase inhibitor", Eur. J. Biochem. 198(3), 775-781 (1991). http://dx.doi. org/10.1111/j.1432-1033.1991.tb16080.x

[25] N. Fujimoto, R. V. Ward, T. Shinya, K. Iwata, Y. Yamashita and T. Hayakawa, "Interaction between tissue inhibitor of metalloproteinases- 2 and progelatinase A: immunoreactivity analyses", Biochem. J. 313 (Pt3), 827-833 (1996). 